\title{
La aventura de un irreductible
}

\section{Crescenciano Grave}

Jorge Juanes, Historia errática y hundimiento del mundo. Con Heidegger. Contra Heidegger. México, CNCA, Libros Magenta, 2013.

J orge Juanes gusta definirse a sí mismo como un filósofo tachado y, contra sí mismo, en este gesto es más notable el filósofo que la tachadura. El filósofo que destaca no es el esgrimidor de argumentos definitivos que, ensamblados en un discurso totalizante, pretenda cohesionar de manera sistemática sus reflexiones. En la escritura que sustenta su pensamiento sobresale el discurrir tentativo y ensayístico que, sin arredrarse ante las contradicciones que él mismo va tejiendo, desbroza una posible ruta de acceso a lo pensado sin que éste quede aprehendido ni fijado. La escritura del filósofo ensayista se forja al mismo tiempo que acoge lo que se le da a pensar y, en esta acogida, se ahuyenta toda presunción de definitividad a la vez que, paradójicamente, se vislumbra la radicalidad de la acometida.

Además de sus aventuras a contracorriente por la filosofía, Jorge Juanes ha deambulado por la reflexión en torno a la obra de grandes artistas de la modernidad. Las corrientes de sus discursos no se estancan sino que, afortunadamente, sin el menor recato, desbordan sus fronteras. Algunos títulos de su faceta artístico-reflexiva son Leonardo da Vinci. Pintura y sabiduría hermética, Kandinsky/Bacon: pintura del espíritu/pintura de la carne; Artaud/ Dalí: los suicidados del surrealismo y, los dos más destacados para nosotros, Goya y la modernidad como catástrofe y Marcel Duchamp. Itinerario de un desconocido. Este deambular no se determinó, pero sí iluminó los mojones de su recorrido en Territorios del arte contemporáneo. Del arte cristiano al arte sin fronteras. Aquí piensa al arte desde el arte, como un prisma cuya irradiación ilumina los claroscuros de la existencia humana y su estancia en un mundo conmocionado por su propia manera de erigirse en relación con la naturaleza y la historia. Las obras de arte concretas albergan ideas a cuya convocatoria a pensarlas, Juanes acude despojado de prejuicios y ataviado con las potencias de su sensibilidad y su pensamiento - en diálogo con otros pensadores- para trazar su aventura personal de confrontación con el arte. 
La referencia anterior tiene como propósito proponer que el papel que ocupa Territorios del arte contemporáneo en la deriva artístico-reflexiva de su autor, lo juega, en su deriva ensayístico-filosófica, el libro que pone en obra su confrontación con Heidegger. Marx o la crítica de la economía política como fundamento; Hegel o la divinización del Estado; Walter Benjamin: física del graffiti; $T$. W. Adorno. Individuo autónomo-arte disonante y, también para nosotros, los dos más notables de esta deriva: Los caprichos de Occidente y Hölderlin y la sabiduría poética (la otra modernidad) son los volúmenes de una ingente obra a la que viene a sumarse -el título es todo, menos discreto-Historia errática y hundimiento del mundo. Con Heidegger. Contra Heidegger. Este libro -digámoslo desde ahora- puede suscitar polémica en alguna de las aseveraciones interpretativas sobre tal o cual pensador, o se le puede detectar algún error en alguna cita (por ejemplo, el verso de Calderón de la Barca "Pues el delito mayor del hombre es haber nacido" de La vida es sueño se refiere como proveniente de El príncipe constante; $c f$. p. 468). Lo que no debería suceder es que cayera en el marasmo del ninguneo. El libro es una provocadora lectura de la historia de la filosofía occidental, así como un cuestionamiento radical a la modernidad dominante; lectura y cuestionamiento en los cuales el autor de Carta sobre el humanismo es cómplice sin dejar de señalar algunas limitantes de su propia postura. En cualquier caso, Heidegger no aparece como maestro pensador embalsamado a cuya autoridad se acuda para legitimar, cual oráculo, tal o cual propuesta. Por otro lado, pretender resumir todo su contenido, sus vericuetos, las digresiones que aparecen aquí y allá en sus diversos capítulos, es algo que está lejos de nuestro propósito. Podemos sí señalar o apuntar algunas líneas maestras que nos parecen necesarias para su lectura y su discusión.

Historia errática y hundimiento del mundo es un libro que, a su manera, está constituido por varios ensayos en donde aparecen y reaparecen hasta la reiteración casi obsesiva algunos temas que sustentan, como un bajo sostenido, su despliegue y los matices que, problematizándolos, los enriquecen. De entre estos temas quisiéramos destacar la confrontación con la metafísica de la subjetividad y su impronta en dos campos imprescindibles para comprender la modernidad dominante: la tecnociencia, que al subsumir a la naturaleza bajo sus propias categorías subjetivas la convierte en un mero depósito explotable pretendiendo negar en ella toda la otredad subversiva de esa misma identificación, y la política que, amparada en la supuesta constitución general de lo humano, proyecta y realiza un mundo cuyos muros terminan por sofocar la libertad de los individuos.

Con Heidegger y contra Heidegger, Juanes lleva a cabo una confrontación personal con la historia de la metafísica moderna y las repercusiones de la subjetividad -erigida como señor del ser- en el dominio sobre la naturaleza 
y en el dominio del hombre sobre el hombre. La centralidad que la tarea de desmoronar la metafísica moderna tiene en Heidegger no es ninguna novedad; lo que sí constituye un enfoque innovador -al menos entre nosotros- es que el proyecto de destrucción de la metafísica moderna y la necesidad de un nuevo inicio del pensar por parte de Heidegger es analizado aquí junto con la impronta política de su pensamiento. Así, el vínculo de Heidegger con el nazismo no es la ingenuidad suprema de un pensador esencial, sino la respuesta de éste a lo que considera las cabezas terribles de la metafísica convertida en política: el americanismo y el bolchevismo o la democracia y el comunismo. Para Juanes "Heidegger es, ante todo, un pensador de lo político" (p. 17) y, más aún, "Heidegger concibe el pensar en relación directa con determinado compromiso histórico-político" (p. 519).

Se trata de ponerse en el horizonte del pensamiento de Heidegger, hacerse cómplice de su confrontación con la historia de la metafísica y, desde dentro, cuestionarlo. Dice Jorge Juanes: "[...] sigo puntualmente el camino trazado por el maestro de la Selva Negra, teniendo por hilo conductor la problemática central emplazada: el cuestionamiento radical de la metafísica de Occidente, y centro la atención en el examen puntual de la moderna metafísica de la subjetividad y la tecnociencia que se le debe" (p. 16). Para seguir a Heidegger parece inevitable aceptar -así sea bajo protesta (véase la parte dedicada a Platón)- algunos de sus juicios parciales o conclusiones sesgadas. Sin embargo, esta aparente inevitabilidad se resiste en la medida en que, dentro del horizonte del pensamiento de Heidegger, Juanes encuentra ciertos resquicios para incurrir en desviaciones.

Las fuentes manantiales de Heidegger se limitan al mundo griego antiguo y centro europeo, obviamente alemán. Y, sin dejar de reconocer la grandeza de lo que el autor de $\mathrm{El}$ ser y el tiempo obtiene de la recreación interpretativa de su tradición, Juanes recurre a la suya para señalar "lo no pensado por Heidegger": el Renacimiento, en específico dentro del arte, da lugar a potencias modernas que, sofocadas por la Reforma, permanecen como un constante latido capaz de irrumpir en el orden dominante. Estas potencias son "el surgimiento, la afirmación y el despliegue del individuo singular, autónomo y creador, libre de sí y para sí cuya temporalidad finita decide, en primera y última instancia, sus posibilidades existenciales concretas, radicales e ineludibles" (p. 17). Abierto a lo otro, el individuo, desde la afirmación de su libertad y finitud, responde de sí en y frente al mundo.

Habría que recordar aquí un momento que, para algunos y frente a la insistencia de los filósofos por ubicarla en Descartes y Bacon, marca el inicio de la modernidad. El 26 de abril de 1336 el poeta Francesco Petrarca escala el Mont Ventoux y en una carta a Dionigi da Bordo San Sepolcro narra su aventura. La primera frase de la carta dice: "Hoy, llevado sólo por el deseo 
de ver la extraordinaria altura del lugar he subido al monte más alto de esta región". Y, en su descripción de este llevar el ansia de lucidez a las alturas, Petrarca describe su estado de ánimo como un abrazo entre razón y pasión ante la desmesura de lo que se le da a ver; su sublimidad y su melancolía que, a la vez, lo impulsa a la exploración de sí mismo y del mundo. Esta vertiente mediterránea y latina de la modernidad es decisiva para comprender las desviaciones de Juanes respecto a Heidegger.

Otro escollo que conlleva seguir la compañía de Heidegger es la aplanadora en que su horizonte de pensamiento se convierte frente a la historia con la que se confronta. Juanes lo tiene claro.

Heidegger interpreta desde su propia problemática teórica cuanto acomete, trátese de quien se trate: pintores, poetas, pensadores, místicos [...] Problemática que presuntamente supera lo antecedente y, por tanto, opera como tribunal de juicio que aprueba o desaprueba inapelablemente lo juzgado. Los pros y los contras guardan referencia, ya en concreto, con el lugar ocupado por este o aquel pensador en torno a la "destrucción de la historia de la ontología" (metafísica). El modo de preguntar por el qué y el cómo de la metafísica se convierte, así, en el criterio decisivo para situar el alcance de determinado pensador (p. 213).

Este escollo no es menor. En él se pone en juego la discusión de si la obra de tal o cual pensador (Platón, Aristóteles, Descartes, Kant, Hegel, Marx o Nietzsche) contiene o no perspectivas de interpretación que la hagan devenir con una mayor riqueza de la que obtiene fijada desde el horizonte de la historia de la metafísica caracterizada como olvido del despliegue de la pregunta por el ser. El propio Heidegger era orgullosamente consciente de esto. En efecto, al exponer la visión retroactiva de Nietzsche sobre la metafísica anterior al autor de Crepúsculo de los ídolos cuyo discurrir es interpretado en términos de voluntad de poder, Heidegger asume que esto no es una objeción de la cual resulte un rechazo de la posición de Nietzsche sobre la historia de la metafísica por considerar que la deforma. Una característica que distingue a la metafísica es que los pensadores interpretan el pasado desde su propia postura. "También nosotros -dice Heidegger- tenemos que mirar e interpretar el pensar anterior desde el círculo visual de un pensar, el nuestro". ${ }^{2} \mathrm{Y}$, ante esto, Juanes

${ }^{1}$ Cf. Rafael Argullol, Enciclopedia del crepúsculo. Barcelona, Acantilado, 2005, pp. 25-28.

${ }^{2}$ Martin Heidegger, Nietzsche II. Trad. de Juan Luis Vermal. Barcelona, Destino, 2000, p. 98 
se mueve con una soltura un tanto ambivalente: rechaza la lectura moderna de lo antiguo como falto de aquello que justamente aflora en la modernidad; le señala a Heidegger el no escapar de este procedimiento y, sin embargo, no deja de aprovechar sus conclusiones negativas sobre la metafísica moderna. Incluso, por momentos, al identificar la subjetividad con el antropocentrismo, Juanes radicaliza la acusación: "Antropocentrismo delirante, ni quien lo dude, resumido en la pretensión de los hombres de ser dioses. No en balde matan a Dios para ocupar su lugar y crear, faltaba más, un mundo artificial a su imagen y semejanza" (p. 20).

¿Cómo se despliega la metafísica del sujeto y cómo interviene en la política moderna? Platón inició la metafísica al distinguir entre los entes que, en el tiempo, devienen y dejan de ser, y las ideas cuyo ser es verdaderamente ser y de las cuales el mundo sensible es una imagen en movimiento. Este modelo de pensamiento es proseguido por la teología cristiana al considerar a la naturaleza y a los hombres entes creados por el sumo ser y, volviéndose hacia el propio creador del pensamiento, se consolidó en la modernidad con la metafísica del sujeto al alzarse éste como la forma suprasensible que, en tanto condición de posibilidad, determina, conociéndolos o realizándolos, los objetos. Esta proyección termina imponiendo en la naturaleza y en el mundo histórico la propia autocualificación subjetiva alcanzando su culminación en el sistema de Hegel -"Perspectiva comprensiva totalizadora que propicia que los hombres puedan llegar a reconocerse entre sí y con la naturaleza, compartiendo una mutua pertenencia espiritual" (p. 254)- y en el comunismo de Marx. En la exposición de este despliegue, Juanes deslinda a Nietzsche de la interpretación heideggeriana: la ubicación de la voluntad de poder como culminación de la subjetividad moderna la califica como resultado de una "miserable exégesis" (p. 422).

Juanes sitúa a Marx en la trayectoria de la metafísica de la subjetividad y lo justifica argumentando que el comunismo es un "programa histórico-político plenamente estructurado" para alcanzar "el dominio del hombre colectivamente concebido sobre la naturaleza y la historia” (p. 291). Marx es el filósofo que lleva la voluntad transformadora de la modernidad filosófica hasta sus consecuencias radicales. Descartes y los pensadores de la Ilustración francesa, Kant y los idealistas, Fichte y Hegel coinciden en que "comprender implica transformar" (p. 302). Sin embargo, carecen de la mediación que permita incidir directamente en la modificación del mundo, mediación que Marx encuentra en la crítica de la economía política. Los pensadores modernos premarxistas no alcanzan a ver la historicidad de las formas sociales de reproducción capitalista. Marx, por su parte, considera que el capitalismo es una época histórica que hay que superar mediante la realización de la subjetividad social.

Recogiendo el cuestionamiento ilustrado a la teología al considerar que este mundo no es un lugar de pecado y pena para conseguir su redención 
en el más allá, y escuchando la convocatoria racionalista para levantar aquí y ahora un mundo de satisfacción terrenal cuya realidad se vuelve posible por la Revolución industrial, Marx creyó que la producción técnica moderna generaba las bases para el pleno dominio del hombre en el mundo. Y, secundando a Heidegger, para quien "el comunismo representa [...] la cima insuperable del orden civilizatorio antropocéntrico moderno, concretado como nihilismo planetario" (p. 289), Juanes insiste en afirmar que el marxismo es "nihilismo, nihilismo activo en tanto poder intensificador del poder logocéntrico generado por la modernidad. Pudiera hablarse de una apoteosis de la voluntad de dominio colectivizada que reduce la Tierra a mero ente transformable en objeto al servicio del sujeto convertido en demiurgo. Heidegger dio en el clavo: la modernidad devenida comunismo encarna la última posibilidad histórica de relación hombre-ser surgida en el marco de la metafísica occidental" (p. 353). Marx no sólo no cuestiona la metafísica de la subjetividad, sino que piensa "bajo el influjo fetichizado de tal metafísica" (p. 388).

La denuncia del marxismo como un proyecto ligado al destino de la metafisica moderna remite casi en automático a la pregunta: ¿qué pasa con el nacionalsocialismo en cuyo seno militó Heidegger? Juanes no es complaciente con el, para algunos, mero error ingenuo de un pensador grande. El gran pensador no está exento de ser un canalla e investir algunas decisiones de su vida con gestos truculentos. El único atenuante que Juanes encuentra en el compromiso de Heidegger con el nazismo es que el filósofo alemán no profesó el racismo ni el antisemitismo y no compartió "el expansionismo nazi, empeñado en imponer sus mitos institucionalizados a todos los pueblos del mundo, por las buenas o bajo la bota militar" (p. 160). Por lo demás, Heidegger asumió "ciertas propuestas nazis: negación de la democracia y los derechos universales del hombre, necesidad de un Estado centralizado y de un líder fuerte y visionario con capacidad de darse a sí mismo leyes que el pueblo cumpliera a rajatabla, el reconocimiento de pueblos históricos y creadores -Alemania a la cabeza-que deben guiar los destinos del mundo, aunar el trabajo del saber al trabajo del campesino y a la responsabilidad en la lucha patria" (p. 286). Para Heidegger, el nazismo era una expresión de la superioridad espiritual de Alemania y si se distanció de él fue porque el nazismo triunfante no escapó "a la metafísica desarraigante y su hija dilecta, la técnica moderna” (p. 287). Sin embargo, Heidegger mantuvo la esperanza de incidir en la definición espiritual del nazismo -a saber qué signifique eso- al asumirse como el filósofo que "piensa desde el acontecer de la comunidad del pueblo" (p. 18).

Al pensar lo político en vínculo directo con un compromiso históricopolítico, Heidegger se define inequívocamente como filósofo. Dice Juanes: "[...] ojalá se dejara de considerar a Heidegger como filósofo, sabido que gasta cientos de cuartillas en desasirse de la filosofía” (p. 21). Pero él mismo, en 
un ajuste de cuentas con Heidegger, muestra que los cientos de cuartillas no son suficientes.

Aun reconociendo el alcance de su cuestionamiento al antropocentrismo o esencia de la técnica, me parece que, al igual que los filósofos al uso, Heidegger mantiene en pie una figura de pensamiento asentada en términos histórico-comunitarios que, dado su carácter, requiere para su efectuación tanto del maestro pensador guía de los pueblos (Heidegger y su referencia pensante-reuniente encarnada en ontofanías presente-ausentes del ser) como de un órgano superior comandado por dirigentes políticos que atienda, acoja y cumpla los llamados del ser. Órgano superior o Estado que, además, reencarne el ser esencial de pueblos supuestamente esenciales. La conjunción de lo nacional con lo comunitario excéntricamente asumido tendría, así, un nombre propio: nacionalsocialismo (pp. 264-265).

Heidegger, pensador de lo político directamente relacionado con una postura política totalitaria, no sólo no escapó sino que militó en una de las formas más siniestras de la sombra de Siracusa que acompaña a la metafísica desde su nacimiento con Platón.

Los sueños de liberación de la modernidad parecen estancarse en la lucha por controlarla e identificarla establecida entre los totalitarismos de izquierda y de derecha y "el capitalismo sobre la base de la subsunción real del proceso de trabajo al capital en provecho de la acumulación de capital permanentemente incrementada" (p. 504). Para Juanes todos estos sistemas tienen su origen en "el antropocentrismo logocéntrico intrínseco a la metafísica tecnocientífica e instrumental” (p. 504), o sea, en última instancia, en el sujeto supraindividual y "omniabarcante que monopoliza la tarea de pensar, producir y reproducir, ordenar y totalizar el conjunto de las relaciones de los hombres entre sí y con la naturaleza hasta un grado tal que incluso quienes intentamos demoler su hegemonía caemos en sus redes" (pp. 503-504). Desde esta perspectiva, el sujeto moderno pretende oficiar el papel que en la Antigüedad griega ocupó el hado y, en el cristianismo, la providencia: se impone sobre todo con tal poder que parece impedir cualquier resquicio por donde escapar a su dominio.

No obstante, algunos momentos del devenir conflictivo de la misma modernidad muestran la posibilidad de resistir. Para Juanes, estos momentos se concentran en el arte y los artistas modernos -desde el Renacimiento y el romanticismo hasta las vanguardias del siglo $\mathrm{XX}$, sin olvidar a algunos tanteadores en solitario- que han reivindicado y recreado, en su obra y en su propia vida, al "individuo singular y polivalente" (p. 508). Recogiendo esta tradición y asumiéndose como parte de ella, dice Juanes: 
Responsabilidad personal e intempestiva versus fatalidad impersonal y rutinaria; por ahí va la aventura de los irreductibles. Pongamos fin, por ende, a lo petrificado en nombre de la afirmación de lo intempestivo. Día a día, de instante en instante [...] Relación libertaria con uno mismo y con los otros que pone sobre el tapete los tonos anímicos del hombre: dolor, placer, amor y odio; miedo, angustia, pasión, melancolía, exaltación... en soledad, en silencio, o en compañía de los cómplices de nuestra aventura existencial (p. 510).

En la propia existencia se encuentran las potencias para confrontarse con el laberinto del dominio trazando nuestra propia aventura vital. Crear y recrear en el pensar nuestra singularidad finita reconociéndonos exiliados de la unidad rota y diseminada en la multiplicidad diferente $y$, a la vez, en la pertenencia al devenir de lo mismo es una forma de ensayar la tentativa de convertir nuestra libertad en destino. 